\title{
Improvement of the primary efficacy of microwave ablation of malignant liver tumors by using a robotic navigation system
}

\author{
Jan Schaible ${ }^{1}$, Benedikt Pregler ${ }^{1}$, Niklas Verloh ${ }^{1}$, Ingo Einspieler ${ }^{1}$, Wolf Bäumler ${ }^{1}$, \\ Florian Zeman ${ }^{2}$, Andreas Schreyer ${ }^{3}$, Christian Stroszczynski ${ }^{1}$, Lukas Beyer ${ }^{1}$
}

\author{
${ }^{1}$ Department of Radiology, University Medical Center Regensburg, Regensburg, Germany \\ ${ }^{2}$ Center for Clinical Studies, University Medical Center Regensburg, Regensburg, Germany \\ ${ }^{3}$ Department of Radiology, Hospital Brandenburg, Brandenburg, Germany
}

Radiol Oncol 2020; 54(3): 295-300.

Received 17 February 2020

Accepted 3 May 2020

Correspondence to: Dr. Jan Schaible, Department of Radiology, University Hospital Regensburg, 93053 Regensburg, Germany. E-mail: jan.schaible@ukr.de

Disclosure: No potential conflicts of interest were disclosed.

\begin{abstract}
Background. The aim of the study was to assess the primary efficacy of robot-assisted microwave ablation and compare it to manually guided microwave ablation for percutaneous ablation of liver malignancies.

Patients and methods. We performed a retrospective single center evaluation of microwave ablations of 368 liver tumors in 192 patients ( 36 female, 156 male, mean age 63 years). One hundred and nineteen ablations were performed between $08 / 2011$ and $03 / 2014$ with manual guidance, whereas 249 ablations were performed between 04/2014 and 11/2018 using robotic guidance. A 6-week follow-up (ultrasound, computed tomography and magnetic resonance imaging) was performed on all patients.

Results. The primary technique efficacy outcome of the group treated by robotic guidance was significantly higher than that of the manually guided group ( $88 \%$ vs. $76 \% ; p=0.013$ ). Multiple logistic regression analysis indicated that a small tumor size $(\leq 3 \mathrm{~cm})$ and robotic guidance were significant favorable prognostic factors for complete ablation. Conclusions. In addition to a small tumor size, robotic navigation was a major positive prognostic factor for primary technique efficacy.
\end{abstract}

Key words: interventional radiology; robotic assistance; microwave ablation; liver tumor

\section{Introduction}

Local ablation therapy has been established as a suitable alternative to resection for the treatment of tumors in the liver, lung, kidney and bone. It is considered a curative treatment for hepatocellular carcinoma (HCC) and can prolong the survival of patients with unresectable colorectal liver metastases. ${ }^{1,2}$

In recent years, microwave ablation (MWA), which is a thermal ablation method, has increasingly been used as an alternative to radiofrequency ablation (RFA). Although there are only a few studies that have compared MWA and RFA, MWA seems to have an advantage for the treatment of large tumors and tumors near vessels owing to its higher energy output. ${ }^{3-5}$ Although the local recurrence rate has decreased owing to technological advances such as the development of multi-applicator systems for MWA and increasing application experience, surgical resection still seems superior with respect to local tumor control..$^{6-9}$

To achieve optimal therapy results with the best possible local tumor control, it is extremely important to obtain complete ablation while maintaining a sufficient safety distance. ${ }^{10}$ Although there 
are still no uniform guidelines for the minimum safety margin (distance between treated tumor and ablation margin), most operators assume a safety margin of approximately $0.5-1 \mathrm{~cm} \cdot{ }^{11-13}$ To achieve this, the microwave applicator (antenna) must be positioned with millimeter precision, which can be very challenging, especially in the case of several overlapping ablation areas. In addition to the common freehand placement, modern navigation systems have been introduced to allow 3D planning and precise antenna placement. ${ }^{14,15}$

Unfortunately, there are only a few studies of the use of navigation systems, and often only with a small number of patients. Although it has been shown that modern navigation systems enable very accurate antenna placement, it is not yet clear whether this also leads to improved primary efficacy of the technique. ${ }^{14,16,17}$ Therefore, the aim of this study was to compare the primary efficacy of robotic-guided ablation with that of manually guided ablation, as evidenced by magnetic resonance imaging (MRI) follow-up after 6 weeks.

\section{Patients and methods}

\section{Study design and participant selection}

The indications for percutaneous tumor ablation were established by a multi-disciplinary tumor board. The following exclusion criteria were applied: coagulation disorders not amendable to substitution; portal vein, hepatic vein or inferior vena cava invasion; extrahepatic metastases; and multifocal hepatic disease not amenable to complete ablation.

A total of 192 patients underwent either freehand or robotic guided microwave ablation from 08/2011 to 11/2018, inclusive. All procedures were performed by the same three experienced interventional radiologists (blinded).

\section{Ethical approval}

This single-center retrospective observational study was approved by the local ethics committee. All procedures performed in studies involving human participants were in accordance with the ethical standards of the institutional and/or national research committee and with the 1964 Helsinki declaration and its later amendments and the guidelines for Good Clinical Practice from the International Conference on Harmonization. Informed consent was obtained from all individual participants included in the study.

\section{Navigation system and thermoablation procedure}

All microwave ablations were performed under general anesthesia. During CT scans and antenna positioning, control of the respiratory movement was performed by temporary tube disconnection. Arterial and portal venous helical CT scans (Somatom 16 or Definition Egde, Siemens Healthcare, Forchheim, Germany) with a slice thickness of $1 \mathrm{~mm}$ were acquired.

CT fluoroscopy was used for ablations without navigation support, an acquisition mode that allows continuous image update using in-room table control. After the initial 2-phase planning CT, the antenna was placed during repeated temporary breath holds. To verify the correct antenna placement, one unenhanced CT was obtained before starting the ablation. If necessary, the antenna was repositioned until the whole tumor volume was covered.

When using robot navigation, the initial $\mathrm{CT}$ data was sent to the navigation system (Maxio, Perfint Healthcare, Chennai, India). ${ }^{18,19}$ The desired ablation area and the antenna entry point were defined using the planning software, and the trajectory was visualized. If necessary, multiple antenna positions were planned with overlapping ablation zones. After approval of the plan, the robotic arm was automatically positioned over the patient and the antenna was positioned using the targeting device during breath hold. The probes were pushed forward manually along the preplanned path while held by the robotic needle holder. Before ablation, a CT scan was performed and the antenna position was verified by overlaying it with the planned trajectory. Consistent docking and absolute registration of the robotic device was performed using a base plate fixed on the ground. The navigation system is connected to the local PACS as a DICOM node. The images are automatically pushed to the navigation system by an auto transfer task after successful reconstruction of the $1 \mathrm{~mm}$ images in the CT scanner.

For ablation, either the Acculis Microwave Tissue Ablation (MTA) System (AngioDynamics, Latham, NY, USA; Accu2i pMTA Applicator 1.8 mm diameter in 14 or $19 \mathrm{~cm}$ length) or the Emprint Ablation System (Medtronic, Minneapolis, USA; Emprint ${ }^{\mathrm{TM}}$ Percutaneous Antennas $1.8 \mathrm{~mm}$ diameter in 15 or $20 \mathrm{~cm}$ length) was used, depending on tumor configuration and relationship to the surrounding tissue. By comparison of the expected ablation zone in the unenhanced scan (typically 
TABLE 1. Patient characteristics

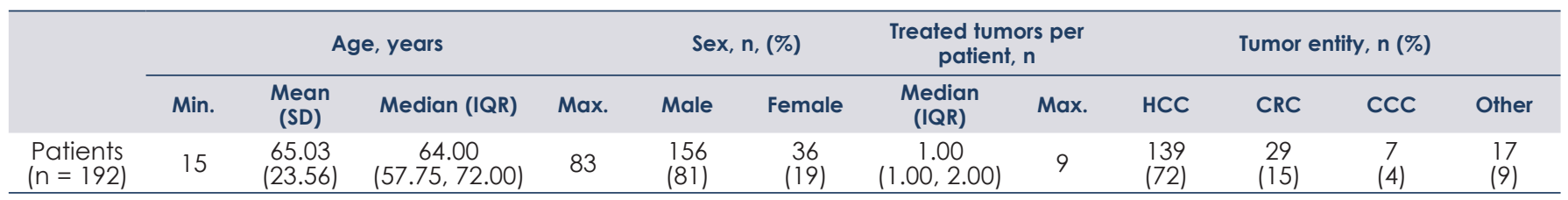

$\mathrm{CCC}=$ cholangiocellular carcinoma; $\mathrm{CRC}=$ colorectal liver metastasis; $\mathrm{HCC}=$ hepatocellular carcinoma; $I Q R=$ interquartile range; $\mathrm{SD}=$ standard deviation

TABLE 2. Tumors treated using freehand and robotic guidance

\begin{tabular}{|c|c|c|c|c|c|c|c|c|c|c|c|c|c|c|c|c|}
\hline \multirow{2}{*}{$\begin{array}{l}\text { Ablation } \\
\text { technique }\end{array}$} & \multicolumn{3}{|c|}{ Long axis, mm } & \multicolumn{9}{|c|}{ Liver segment, n (\%) } & \multicolumn{2}{|c|}{ Device, n (\%) } & \multicolumn{2}{|c|}{ Primary efficacy, n (\%) } \\
\hline & Min & $\begin{array}{l}\text { Mean } \\
\text { (SD) }\end{array}$ & $\operatorname{Max}$ & I & II & III & IVa & $\mathrm{IVb}$ & V & VI & VII & VIII & Acculis & Emprint & Complete & $\begin{array}{c}\text { In- } \\
\text { complete }\end{array}$ \\
\hline $\begin{array}{l}\text { Freehand } \\
(n=119)\end{array}$ & 4 & $\begin{array}{c}19.79 \\
(12.42)\end{array}$ & 85 & $\begin{array}{c}1 \\
(1)\end{array}$ & $\begin{array}{l}10 \\
(8)\end{array}$ & $\begin{array}{c}16 \\
(13)\end{array}$ & $\begin{array}{c}16 \\
(13)\end{array}$ & $\begin{array}{c}9 \\
(8)\end{array}$ & $\begin{array}{l}13 \\
(11)\end{array}$ & $\begin{array}{l}17 \\
(14)\end{array}$ & $\begin{array}{c}15 \\
(13)\end{array}$ & $\begin{array}{c}22 \\
(18)\end{array}$ & $\begin{array}{c}65 \\
(55)\end{array}$ & $\begin{array}{c}54 \\
(45)\end{array}$ & $\begin{array}{c}9 \\
(76)\end{array}$ & $\begin{array}{c}28 \\
(24)\end{array}$ \\
\hline $\begin{array}{l}\text { Robotic } \\
\text { guidance } \\
(n=249)\end{array}$ & 3 & $\begin{array}{c}18.78 \\
(10.78)\end{array}$ & 64 & $\begin{array}{c}6 \\
(2)\end{array}$ & $\begin{array}{c}24 \\
(10)\end{array}$ & $\begin{array}{l}20 \\
(8)\end{array}$ & $\begin{array}{c}26 \\
(10)\end{array}$ & $\begin{array}{l}16 \\
(6)\end{array}$ & $\begin{array}{c}38 \\
(15)\end{array}$ & $\begin{array}{l}36 \\
(14)\end{array}$ & $\begin{array}{c}36 \\
(14)\end{array}$ & $\begin{array}{c}47 \\
(19)\end{array}$ & $\begin{array}{r}143 \\
(57)\end{array}$ & $\begin{array}{l}106 \\
(43)\end{array}$ & $\begin{array}{l}219 \\
(88)\end{array}$ & $\begin{array}{l}30 \\
(12)\end{array}$ \\
\hline
\end{tabular}

SD = standard deviation

hypodense) to the initial tumor in the planning scan. If there was suspicion of insufficient ablation margin repositioning was performed.

After ablation and track ablation, all patients underwent a noncontrast multislice CT scan of the liver to detect complications.

\section{Imaging follow-up}

All patients underwent our standard follow-up scheme after 6 weeks including CT, MRI with hepatospecific contrast agent and ultrasound. Further follow-up investigations were only carried out using MRI and ultrasound for radiation protection. The radiographic adjudication/visual assessment of the complete success of the ablation was retrospectively determined in consensus by two experienced radiologists (blinded). The primary technique efficacy was defined as the percentage of the target tumors that were successfully eradicated following the initial procedure as evidenced in the 6-week follow up according to the standardization of terminology by Ahmed et al. ${ }^{20}$

\section{Statistical analysis}

R 3.51 was used to perform all statistical calculations. A p-value of $\mathrm{p} \leq 0.05$ was considered the cutoff point of statistical significance. For multivariate analysis of primary efficacy using nested data (multiple ablations per patient in some cases), we applied generalized estimation equations (GEEs).

\section{Results}

\section{Patient characteristics}

A total of 192 patients (156 male) were included in the study (Table 1 ). The median age was 64 years (range: 57-72). In total, 264 ablation sessions were performed with a median number of treatment sessions per patient of 1 (range: $1-4$ ). 137 patients required one session, 41 patients required two sessions and the remaining patients required three or more sessions. The median number of tumors treated per patient was 1 (range: $1-9$ ).

\section{Tumor characteristics}

A total of 368 tumors spread across all liver segments were treated using MWA and either robotic-assistance or CT fluoroscopy (Table 2). The two most frequent tumor entities were hepatocellular carcinoma $(n=271)$ and liver metastasis of colorectal carcinoma $(n=54)$, followed by cholangiocellular carcinoma $(n=18)$. The median tumor size was $16 \mathrm{~mm}$, with 59 tumors larger than $30 \mathrm{~mm}$.

\section{Primary technique efficacy and prognostic factors}

The primary efficacy rate using robotic guidance was $88 \%$, i.e., 219 of the 249 tumors were covered completely by the ablation volume. Needle repositioning was necessary in 92 of 249 ablations (37\%). In contrast, the primary efficacy rate for freehand 
TABLE 3. Influence of tumor characteristics on primary efficacy

\begin{tabular}{llllll}
\hline Predictor & & Estimate & Std.err & Wald & p-value \\
\hline \multirow{2}{*}{ Long axis, $\mathrm{mm}$} & $\leq 30$ & Reference & & & \\
& $>30$ & -0.8717 & 0.3657 & 5.68 & 0.0171 \\
Guidance & Freehand & Reference & & & \\
& Robotic & 0.8064 & 0.3256 & 6.13 & 0.0133 \\
& HCC & Reference & & & \\
Tumor entity & CRC & 0.2922 & 0.4483 & 0.42 & 0.5145 \\
& CCC & 0.0665 & 0.6524 & 0.01 & 0.9188 \\
& Other & 0.0832 & 0.5228 & 0.03 & 0.8736 \\
& I & Reference & & & \\
& II & -0.3956 & 1.0798 & 0.13 & 0.7141 \\
& III & -0.0449 & 1.1025 & 0.00 & 0.9675 \\
& IVa & 0.2688 & 1.1180 & 0.06 & 0.8100 \\
\cline { 2 - 5 } Liver segment & IVb & -0.2539 & 1.1597 & 0.05 & 0.8267 \\
& $\mathrm{~V}$ & 0.5961 & 1.1285 & 0.28 & 0.5974 \\
& $\mathrm{VI}$ & 0.9036 & 1.1736 & 0.59 & 0.4413 \\
& $\mathrm{VII}$ & 0.0656 & 1.1090 & 0.00 & 0.9528 \\
& $\mathrm{VIII}$ & -0.1069 & 1.0929 & 0.01 & 0.9221 \\
\hline
\end{tabular}

$\mathrm{CCC}=$ cholangiocellular carcinoma; $\mathrm{CRC}=$ colorectal liver metastasis $; \mathrm{HCC}=$ hepatocellular carcinoma; Wald $=\times 2$ test for the coefficients

TABLE 4. Monte Carlo simulation of primary technique efficacy rate depending on tumor size and antenna guidance

\begin{tabular}{lllll}
\hline $\begin{array}{l}\text { Long } \\
\text { axis, } \\
\text { mm }\end{array}$ & Guidance & Cl-2.5\% & Median & Cl-97.5\% \\
\hline$\leq 30$ & Freehand & 0.60 & 0.75 & 0.86 \\
$>30$ & Freehand & 0.34 & 0.55 & 0.76 \\
$\leq 30$ & Robotic & 0.78 & 0.87 & 0.92 \\
$>30$ & Robotic & 0.55 & 0.74 & 0.87 \\
\hline
\end{tabular}

$\mathrm{Cl}-2.5 \%$ and $\mathrm{Cl}-97.5 \%$ = the central interval bounds at the lower 2.5 and upper 97.5 percentiles, respectively; Median = the simulated distribution's median

ablation was $76 \%$ (91 of 119 tumors). Logistic regression was performed to investigate whether tumor characteristics (size, entity and location) and the type of guidance (robotic or freehand) can impact primary technique efficacy (Table 3).

Compared with tumor size $\leq 3 \mathrm{~cm}$, tumor size $>$ $3 \mathrm{~cm}$ was a significantly unfavorable prognosticator of primary technique efficacy (odds ratio 0.42; $\mathrm{p}=0.02)$. Compared with freehand antenna placement, robotic guidance was a significant favorable prognostic factor (odds ratio 2.24; $\mathrm{p}=0.01$ ). Table 4 shows estimations of the primary technique efficacy for robotic and freehand guidance.

\section{Adverse events}

$141(80.11 \%)$ of the robotic-guided and $62(70.45 \%)$ of the CT-fluoroscopy-guided procedures were performed without any adverse events. Grade I (mild), II (moderate) and III (severe) adverse events occurred in 9 (5.11\%), $6(3.41 \%)$ and $1(0.57 \%)$ of the robotic-guided procedures, respectively, and 3 $(3.41 \%), 3(3.41 \%)$ and $1(1.14 \%)$ of the freehandguided procedures, respectively.

Grade IV (life-threatening) adverse events occurred in $1(0.57 \%)$ of the robotic-guided procedures and $2(2.27 \%)$ of the freehand-guided procedures. The patient in the robotic-guided group suffered an injury to the 10th intercostal artery during ablation, which led to persistent bleeding and had to be treated with embolization. One of the patients in the freehand group, who had previously undergone partial liver resection and a consecutive Chilaiditi situation, had a perforation of a prolapsed intestinal loop that had to be surgically overstitched. The other patient in the freehand group suffered from bleeding from the 7th and 8th intercostal artery after ablation, which had to be closed by embolization.

Treatment-related patient death (Grade V) occurred in $1(0.57 \%)$ of the robotic-guided procedures and $0(0.00 \%)$ of the freehand guided procedures. A patient that had a previous liver and kidney transplant developed severe cholangitis two days after ablation and subsequent liver and kidney failure with lactate acidosis, which could not be controlled despite ultima ratio crush hepatectomy.

There was no significant difference in the frequency of adverse events ( $p=0.07)$ between the two groups.

\section{Discussion}

In recent years, the importance of local ablative procedures for the treatment of liver tumors has steadily increased. It is well-known that an initial complete response is associated with improved survival from hepatocellular carcinoma and colorectal liver metastasis. ${ }^{10,21}$ Therefore, the exact placement of the antenna is critically important to achieve complete ablation with a sufficient safety margin.

Navigation procedures are increasingly used to assist with accurate antenna placement. We have also switched from manual guidance to navigation in almost all cases. Only in very few cases (tumor 
right below diaphragm or right next to stomach) we switched to manual placement for better control. Although a very high accuracy of the robotsupported placement has already been shown ${ }^{14,18}$ until now, it has not been clear whether this improves the primary efficacy, i.e., the percentage of target tumors successful eradicated.

Studies have shown that the robotic-guided approach improves the accuracy of targeting the tumor, reduces patient radiation dose and increases procedural performance when compared with conventional non-navigated antenna placement. ${ }^{14,22-24}$ Other studies claim that there is no statistically significant reduction in the dose between the robotic-assisted and conventional method. ${ }^{25}$ In one of our earlier studies, we showed that robotic assistance for liver tumor ablation reduces the patient radiation dose and allows a fast positioning of the microwave applicator with high accuracy. ${ }^{18}$ Due to the small number of patients $(n=46)$ we could not show any significant difference in the primary efficacy rate. In one of our previous studies, we were able to show that additional overhead does not save time in the case of only one tumor, and that savings can only be expected in complex procedures. ${ }^{26}$

Although these previous studies have shown that antenna placement is highly accurate when using a robotic-guided navigation system, the impact of higher accuracy on the technical efficacy has not been investigated. In this study, we show for the first time in a large patient population (249 tumors ablated using robotic assistance) that robotic guidance is associated with a significantly higher technical success rate (primary efficacy rate using robotic guidance was $88 \%$, primary efficacy rate for freehand ablation was $76 \%$ ). From our point of view, this difference is very remarkable, because we had many years of expertise in manual guidance and still managed to achieve this improvement with the new type of navigation.

Although the large patient population indicates a high significance, some limitations have to be discussed. One aspect that needs to be considered is that interindividual differences could play a role. However, from our point of view, the high experience and the large number of ablations of each interventionalist speak against great interindividual differences. In addition, the learning curve also plays a role, which undoubtedly occurs over time, as Beermann et al. also stated. ${ }^{27}$

In summary, our study was the first to show that robotic-guided antenna placement goes hand in hand with a higher primary efficacy.

\section{References}

1. Kokudo $\mathrm{N}$, Hasegawa $\mathrm{K}$, Akahane $\mathrm{M}$, Igaki $\mathrm{H}$, Izumi $\mathrm{N}$, Ichida $\mathrm{T}$, et al. Evidence-based clinical practice guidelines for hepatocellular carcinoma: The Japan Society of Hepatology 2013 update (3rd JSH-HCC Guidelines). Hepatol Res 2015; 45: n/a-n/a. doi: 10.1111/hepr.12464

2. Ruers T, Van Coevorden F, Punt CJ, Pierie JE, Borel-Rinkes I, Ledermann JA, et al. Local treatment of unresectable colorectal liver metastases: results of a randomized Phase II trial. JNCI J Natl Cancer Inst 2017; 109: 9. doi: 10.1093/ jnci/djx015

3. Facciorusso A, Di Maso M, Muscatiello N. Microwave ablation versus radiofrequency ablation for the treatment of hepatocellular carcinoma: a systematic review and meta-analysis. Int J Hyperth 2016; 32: 339-44. doi: $10.3109 / 02656736.2015 .1127434$

4. Vogl TJ, Farshid P, Naguib NN, Zangos S, Bodelle B, Paul J, et al. Ablation therapy of hepatocellular carcinoma: a comparative study between radiofrequency and microwave ablation. Abdom Imaging 2015; 40: 1829-37. doi: 10.1007/s00261-015-0355-6

5. Abdelaziz AO, Nabeel MM, Elbaz TM, Shousha HI, Hassan EM, Mahmoud $\mathrm{SH}$, et al. Microwave ablation versus transarterial chemoembolization in large hepatocellular carcinoma: prospective analysis. Scand J Gastroenterol 2015; 50: 479-84. doi: 10.3109/00365521.2014.1003397

6. Chu KF, Dupuy DE. Thermal ablation of tumours: biological mechanisms and advances in therapy. Nat Rev Cancer 2014; 14: 199-208. doi: 10.1038/ $\operatorname{nrc3672}$

7. van Amerongen MJ, Jenniskens SFM, van den Boezem PB, Fütterer JJ, de Wilt JHW. Radiofrequency ablation compared with surgical resection for curative treatment of patients with colorectal liver metastases - a metaanalysis. HPB 2017; 19: 749-56. doi: 10.1016/j.hpb.2017.05.011

8. Wang $Y$, Luo $Q$, Li $Y$, Deng S, Wei S, Li X. Radiofrequency ablation versus hepatic resection for small hepatocellular carcinomas: a meta-analysis of randomized and nonrandomized controlled trials. PLoS One 2014; 9: e84484. doi: 10.1371/journal.pone.0084484

9. Xu Q, Kobayashi S, Ye X, Meng X. Comparison of hepatic resection and radiofrequency ablation for small hepatocellular carcinoma: a meta-analysis of 16,103 patients. Sci Rep 2015; 4: 7252. doi: 10.1038/srep07252

10. Sala M, Llovet JM, Vilana R, Bianchi L, Solé M, Ayuso C, et al. Initial response to percutaneous ablation predicts survival in patients with hepatocellular carcinoma. Hepatology 2004; 40: 1352-60. doi: 10.1002/hep.20465

11. Kurilova I, Gonzalez-Aguirre A, Beets-Tan RG, Erinjeri J, Petre EN, Gonen $\mathrm{M}$, et al. Microwave ablation in the management of colorectal cancer pulmonary metastases. Cardiovasc Intervent Radiol 2018; 41: 1530-44. doi: 10.1007/s00270-018-2000-6

12. Ke S, Ding XM, Qian XJ, Zhou YM, Cao BX, Gao K, et al. Radiofrequency ablation of hepatocellular carcinoma sized $>3$ and $\leq 5 \mathrm{~cm}$ : is ablative margin of more than $1 \mathrm{~cm}$ justified? World J Gastroenterol 2013; 19: 7389-98. doi: 10.3748/wjg.v19.i42.7389

13. Schaible J, Pregler B, Baümler W, Einspieler I, Jung EM, Stroszczynski C, et al. Safety margin assessment after microwave ablation of liver tumors: interand intrareader variability. Radiol Oncol 2020; 54(3): 295-300.; 54: 57-61. doi: 10.2478/raon-2020-0004

14. Mbalisike EC, VogI TJ, Zangos S, Eichler K, Balakrishnan P, Paul J. Imageguided microwave thermoablation of hepatic tumours using novel robotic guidance: an early experience. Eur Radiol 2015; 25: 454-62. doi: 10.1007/ s00330-014-3398-0

15. Bale R, Widmann G, Schullian P, Haidu M, Pall G, Klaus A, et al. Percutaneous stereotactic radiofrequency ablation of colorectal liver metastases. Eur Radiol 2012; 22: 930-37. doi: 10.1007/s00330-011-2314-0

16. Beyer LP, Michalik K, Niessen C, Platz Batista da Silva N, Wiesinger I, Stroszczynski C, et al. Evaluation of a robotic assistance-system for percutaneous computed tomography-guided (CT-guided) facet joint injection: a phantom study. Med Sci Monit 2016; 22: 3334-9. doi: 10.12659/ MSM.900686

17. Solomon SB, Patriciu A, Bohlman ME, Kavoussi LR, Stoianovici D. Robotically driven interventions: a method of using CT fluoroscopy without radiation exposure to the physician. Radiology 2002; 225: 277-82. doi: 10.1148/ radiol. 2251011133 
18. Beyer LP, Pregler B, Niessen C, Dollinger M, Graf BM, Müller M, et al. Robot-assisted microwave thermoablation of liver tumors: a single-center experience. Int J Comput Assist Radiol Surg 2016; 11: 253-9. doi: 10.1007/ s11548-015-1286-y

19. Beyer LP, Pregler B, Michalik K, Niessen C, Dollinger M, Müller M, et al. Evaluation of a robotic system for irreversible electroporation (IRE) of malignant liver tumors: initial results. Int J Comput Assist Radiol Surg 2017; 12: 803-9. doi: 10.1007/s11548-016-1485-1

20. Ahmed M, Solbiati L, Brace CL, Breen DJ, Callstrom MR, Charboneau JW, et al Image-guided tumor ablation: standardization of terminology and reporting criteria - 10-year update. Radiology 2014; 273: 241-60. doi: 10.1148/ radiol.14132958

21. Solbiati L, Ahmed M, Cova L, lerace T, Brioschi M, Goldberg SN. Small liver colorectal metastases treated with percutaneous radiofrequency ablation: local response rate and long-term survival with up to 10-year follow-up. Radiology 2012; 265: 958-68. doi: 10.1148/radiol.12111851

22. Koethe $Y, X u$ S, Velusamy G, Wood BJ, Venkatesan AM. Accuracy and efficacy of percutaneous biopsy and ablation using robotic assistance under computed tomography guidance: a phantom study. Eur Radiol 2014; 24: 723-30. doi: 10.1007/s00330-013-3056-y

23. Hiraki T, Matsuno T, Kamegawa T, Komaki T, Sakurai J, Matsuura R, et al. Robotic insertion of various ablation needles under computed tomography guidance: accuracy in animal experiments. Eur J Radiol 2018; 105: 162-7. doi: 10.1016/j.ejrad.2018.06.006

24. Heerink WJ, Ruiter SJS, Pennings JP, Lansdorp B, Vliegenthart R, Oudkerk M et al. Robotic versus freehand needle positioning in CT-guided ablation of liver tumors: a randomized controlled trial. Radiology 2019; 290: 826-32. doi: 10.1148/radiol.2018181698

25. Abdullah BJJ, Yeong CH, Goh KL, Yoong BK, Ho GF, Yim CCW, et al. Roboticassisted thermal ablation of liver tumours. Eur Radiol 2015; 25: 246-57. doi: 10.1007/s00330-014-3391-7

26. Beyer LP, Lürken L, Verloh $N$, Haimerl M, Michalik K, Schaible J, et al. Stereotactically navigated percutaneous microwave ablation (MWA) compared to conventional MWA: a matched pair analysis. Int J Comput Assist Radiol Surg 2018; 13: 1991-7. doi: 10.1007/s11548-018-1778-7

27. Beermann M, Lindeberg J, Engstrand J, Galmén K, Karlgren S, Stillström D, et al. 1000 consecutive ablation sessions in the era of computer assisted image guidance - lessons learned. Eur J Radiol Open 2019; 6: 1-8. doi: 10.1016/j. ejro.2018.11.002 